Island Studies Journal, Vol. 9, No. 1, 2014, pp. 155-166

\title{
Not continents in miniature: islands as ecotones
}

\author{
John R. Gillis \\ Professor History Emeritus \\ Rutgers University NJ, USA \\ gottgillis@,cs.com
}

\begin{abstract}
Islands are usually thought of as being territorial-like continents, but on a smaller scale. Yet, they differ from continents in one fundamental regard: their relationship to water. Islands must be understood as ecotones, a concept of increasing importance to the environmental sciences in recent years, but not well known to island studies scholars. An ecotone is a place where two ecosystems connect and create a unique environment different from both. It therefore illuminates aspects of island life that are obscured when we treat islands as bounded territorial units constituting a singular ecosystem. Continents may contain one or more ecotones; but islands, especially smaller ones, are dominated by the ecotone where land meets sea. The littoral ecotone helps explain many of the distinctive qualities of island economies and the adaptability, dynamism, and resilience of island societies. It adds to the extensive revisionist literature that has already challenged the myth of island isolation, boundedness, and remoteness.
\end{abstract}

Keywords: continent; ecotone; edge species; islands; littoral; margin; terraqueous

(C) 2014 - Institute of Island Studies, University of Prince Edward Island, Canada.

\section{Introduction}

Islands are different from all other lands in so far as they are defined by water. Beer (1990, $\mathrm{p}$. 271) notes that "the concept "island" implies a particular and intense relationship between land and water." No wonder, for the word itself comes from the Old English igland, ig meaning water. As waterlands, islands have not one, but several ecosystems. They are ecotonal, places were ecosystems intersect, overlap and exist in creative tension with one another. Islands are never the clearly bounded entities we imagine them to be. Carson $(1998$, p. 1) rightly insisted that "always the edge of the sea remains an elusive and indefinable boundary."

We will never understand island environments until we stop treating them as exclusively territorial, as continents in miniature (Turner, Davidson-Hunt, and O'Flaherty, 2003; DeLoughrey, 2013). My interest in the ecotonal nature of islands arises from my work on shores, the archetypal ecotone, where marine and terrestrial ecosystems meet. There are large islands whose shores have little impact on their interiors, but, for most islands, where the shore to interior ratio is greater, the ecotone is a largely underexplored dimension of island life. Interest in ecotones is relatively recent and still underdeveloped, but intersects with a growing awareness of all things once regarded as marginal, both in the sciences and the humanities. 
Historians of littorals will find the notion of the ecotone particularly useful to their work. Michael Pearson, historian of the Indian Ocean and its shores, has taken the lead in emphasizing the unique character of those places that belong to both sea and land. He rejects the notion that littorals divide land and water. Instead, he argues that they porous and connective. They produce unique societies, marked by diversity and dynamism,

Islands are where we are most likely to find littoral societies. Indeed, on the smaller ones there would be nothing but coastal people, for the sea permeates the whole area (Pearson, 2006, p. 358).

Littorals, like ecotones, should to be treated as an autonomous region, with its own unique characteristics, a history and geography all their own (Pearson, 2005). While Pearson does not deploy the notion of ecotone specifically, his treatment of littorals as fluid, porous zones is wholly compatible with it. Rejecting the ideas that the shore is merely the edge of something else, he rescues it from the condescension of both maritime and continental historians, who have always treated it as a dividing line, a mere threshold uninteresting in itself. As he and others like Philip Steinberg have shown, the shore may be a margin between land and water; but it is never marginal to the history of humankind, especially in the pre-modern period. (Steinberg, 2001) Indeed, littorals suggest why we should pay more attention to all kinds of margins currently neglected by historians and social scientists.

\section{Islands versus continents}

Our misunderstandings of the relationship between land and water are the product of western science and culture (e.g. Gillespie \& Clague, 2009). In the ancient world, land and water were never as differentiated as they are today. To the ancient and medieval Greeks, archipelago meant the Aegean Sea itself, only later referring to the islands contained within. Now it refers to any group of isles (Stratford, Baldacchino, McMahon, Farbotko, \& Harwood, 2011; Hayward, 2012). Ancient and medieval Europeans viewed the world as archipelagic, if not aquapelagic, one large Orbis Terrarum surrounded by many smaller isles (Nunn, 2007, p. 132). Columbus voyaged in anticipation of island hopping to Asia. His chance discovery of a landmass that could not be sailed around or through called the archipelagic vision into question, and, by the eighteenth century, the modern distinction between islands and continents had come to be considered a fact of nature (Lewis \& Wigen, 1997, chapter 1).

Still, the ancient view of the world as terraqueous persisted in many parts of the world. Until the eighteenth century, shores were considered waterlands, an indefinite zone of everchanging dimension. It was not until then that term "coast" ceased to be a verb, referring to alongshore sailing, and became a noun, applied initially to certain edges of continents, though rarely to the shores of islands. The coast line was a cartographer's fiction, superimposed on the fractal shore by the authorities of the newly emerging nation state, who seized upon the idea of the coast as confirmation of continents' claim to be a natural unit of advanced civilization.

People who live on continents get in the habit of regarding the ocean as journey's end, the full stop at the end of the trek (Raban, 1988, p. 300). 
But islands afford another perspective, one that takes water into account. "People who live on islands, especially on small islands, the sea is always the beginning ... Islanders also know the sea goes on and on, in a continuous loop of shoreline and life, without a terminus" (ibid.). But it is the continentalist view of history and geography that has come to dominate in modern times, first in the West and then around the world. When European and American imperialists entered the Pacific in the eighteenth century, they set boundaries around islands that made no sense to indigenous peoples used to seeing the water as connecting rather than dividing.

In the modern era, islands have been treated as miniature continents, emphasizing "the bounded landscape at the expense of the broader seascape" (Rainbird, 1999, p. 232). Environmentalists have focused either on land or on sea, paying much less attention to ecotones that connect them. More attention has been paid to terrestrial ecosystems, Oceanography is the last born of the modern sciences, always playing catch-up. There exists what might be called a blue hole in environmental history, which has consistently ignored the 7/10ths of our globe's surface covered by water, a biosystem estimated to constitute 98 percent of our biosphere. Western civilization has largely ignored the sea except as something to pass over. The cartographic tradition of drawing lines where none exist and colouring blue all that lies offshore reinforced the notion of an elemental difference between land and water.

Lands were deemed to have histories, but the sea was assumed to exist outside of time. Modern historical writing has been largely continentalist in orientation. For most historians, history begins and ends at the coast. Even maritime history has been largely concerned with what happens on rather than in the sea. Having played an major role in historical development, islands have suffered from similar, continentalist condescension. Only recently have they reclaimed their proper place in time, largely through the efforts of global historians (Gillis, 2004). Now it falls to environmental historians to reveal their links to the larger environment.

\section{Challenge of environmental history}

Reformulating and revitalizing environmental history requires that we not only go offshore, but that we follow water wherever it takes us. More attention is due to watersheds and estuaries, to brown as well as blue water. We must follow migratory species, including humans, back and forth across the tide line, for island environmental history must be a history without borders, a history in depth and breadth, where earth, wind and water are in constant motion and interaction, and humankind plays a key role. Such a history will be more liquid, but still grounded in the actual experiences of islands and islanders. We need to muddy the waters by bringing earth, water, and humanity together.

The challenge to environmental historians is to find the apt temporal and spatial frames, to reset the boundaries of their subject so as not to mistake momentary and local phenomena for the large processes that have had such a profound impact on island life. Rachel Carson rejects Alexander Pope's notion of man's [sic] earthly existence: "His time a moment, and a point his space" (Carson, as quoted in Gasstner, 1983, p. 64). Instead, she urges us to consider deep time and broad horizons when it comes to studying environments, even those as supposedly bounded and static as islands (Gasstner, 1983, p. 64). 
It is particularly important to understand that island history is a co-construction of humans and nature. Nature has shaped islands, but islands also bear the imprint of humankind. It has been said that "it is just as interesting to ask how people make islands as how islands make people" (Broodbank, 1999, p. 234). Islands appeal to us because they appear to be bounded objects which can easily be grasped by the mind's eye. Of all topographies, they are perhaps the most metaphorically powerful. We use the concept of island to describe all kinds of places - mountains, parts of the brain, traffic dividers - when we want to suggest separateness and isolation (Eriksen, 1993). But equating islands with insularity blinds us to their realities, which are by no means disconnected from the world at large.

How islands are perceived varies from culture to culture, and over time within cultures. Islands in the minds of islanders are very different from those perceived by people who dwell in the interiors of mainlands, but not necessarily so different from those in the minds of coastal people, who have a similar relationship to the sea as islanders do. In the past, both islanders and coastal people qualified, along with the flora and fauna they depended on, as edge species, people capable of exploiting the possibilities of the ecotones they occupied. Inlanders can also master margins, taking advantage of multiple environments, but, as industrial agriculture has become increasingly monocultural, interior ecotones have become increasingly rare (Berry, 2007). But it is also important to differentiate people who live on coasts from those who live with them, making their livings by crossing the tideline as fishers, gatherers, or mariners. Today, increasing numbers of people live on the shore, but fewer and fewer know how to live with the sea, in an ecologically sustainable manner.

Environments are not apart from us, but something that we have had a hand in constructing. The scale of an island environment is partly determined by nature, including the patterns of winds and waves that impinge on it; but is also defined by how far its inhabitants range off and onshore in search of resources. Newfoundlanders were traditionally expert at hunting and gathering on both sides of the tideline. In summer, they turn their backs on the interior, but in winter they can be found inland, shooting moose, harvesting berries, felling timber (Pope, 2004, pp. 234-248). In the case of fisheries, the relevant environment is established not just by the migrations of species being pursued but by the range of the fishers. The operative environment of an oyster man or clammer may be relatively narrow in scope, but a deep-sea mariner will engage with several different ecosystems in a single voyage. The whalers of Nantucket, for example, ranged from the Atlantic to the Pacific, meeting a remarkable variety of conditions. Living an ecotonal existence, islanders are amazingly sensitive and adaptable to the conditions of both land and water. Their relationship to nature is by no means passive. Indeed, they have been shaping their own environments for millennia.

\section{Living ecotonally}

While ecotones exist in many places - anywhere two or more ecosystems intersect - they are perhaps most common were land and water meet. They are found along streams and rivers, in wetlands, on the shores of lakes and oceans. Early human settlements were found in such settings, and it has recently been determined that the first developed Homo sapiens made their home in the coastal caves at Pinnacle Point at the southern tip of Africa roughly 165,000 years ago, taking advantage of the nutritional wealth available at the tide line. From there they 158 
migrated alongshore, eventually populating the entire globe. It was along the so-called "kelp highway" that the world was first inhabited by humankind. Ever since, ecotones have been our favoured habitat, just as they are for all other species: birds, fish, as well as other animals. Where ecotones were not provided by nature, we have created them. An ecotone is not a thing, a fact of nature, but a process involving many agents, including humans.

The word 'ecotone' was used in 1904 to indicate a space that separated. By 1926, it had come to be associated with connection, and its current sense of a transitional space. It was first applied to water in the 1960s. Ecotone combines the Latin term eco (derived from the Greek word oikos, meaning house) with tone, which means tension in Greek (Oxford English Dictionary). It is not a passive or static place, but one that is dynamic, belonging as much to history as to nature. Ecotones not only produce the greatest biodiversity, but the greatest rates of change. As Krall (1994, p. 4) puts it,

Change is a fundamental part of all natural communities, even those that seem stable, as the cycles of life and death set into play a succession of regenerating events. But, at the ecotone, change is most evident and inevitable.

It is perhaps not surprising that ecotones have gotten little attention until recently, for so much attention in environmental studies has been focused on equilibria within systems, so little on change as such. Now, in a period of ecological crisis, change demands our attention. In response, the new environmental history has put into motion so many natural features that were once seen as beyond the reach of time. When she wrote her classic, The sea around us, Carson (1951) could still talk of an "incorruptible sea." Today, the language of eternal sea is being displaced by that of the "mortal sea," an acknowledgment of the massive changes that are so evident now, but which were always a part of our marine world (Bolster, 2012).

While the historicization of nature is now proceeding rapidly, it is surprising that ecotones, where change is so evident, have gone largely unnoticed by historians. In part, this is because the change that occurs in an ecotone - like an oceanic tidal shore - appears to be more cyclical than linear. But this, like so much else, is more illusion than reality. Cyclical and linear change are inseparable, and the shore, however much we may wish to turn it into an icon of stability, is one of the most fundamentally altered places on earth. It is high time not just to bring ecotones into history, but to place them at the centre of attention. Like so much that we have consistently defined as "marginal," of little interest in and of themselves, ecotones turn out to be central, not just on the micro but the global scale. They deserve our wholehearted attention, especially when it comes to islands, where ecotones have had so much greater importance than in the case of other land forms, particularly the interiors of continents.

Many of the characteristic features of islands and islanders are the product of islands' ecotonal nature. Things that are often ascribed to islands as territories are in fact the product of their interaction with that which surrounds them. Ecotones are also found on continents, especially at their shores, but also in their interiors along rivers and lakes, on mountain slopes, and at the edges of forests. It is islands quality as waterlands that we should be paying attention to.. There are many ways to explain this, but one that is particularly fruitful is to see island shores as interfaces, making connections between things that might otherwise remain separate. Just as membranes do on a molecular or cellular level, island shores facilitate exchanges that 
are beneficial to all the parties concerned. The place where land meets water has always been a place of trade, not just of commodities but of ideas and languages. Until the early modern era, water was the fastest, most efficient mode of communication; and it remains the cheapest form of material transportation. Before there were ports designed to facilitate commerce, trade took place periodically on beaches, a safe, neutral zone. In what is sometimes called "silent trade," ships would deliver goods to the shore and then stand off, waiting for others to place their counteroffer there. If agreed upon, the exchange would be completed without a word spoken. Until well into the seventeenth century, the European herring trade was conducted at temporary sites that attracted hundreds of fishers, leaving no trace once they finished their business.

Shores were considered extraterritorial, places were strangers could come and go as freely as the fish, birds, and other animals that also made these way stations on their annual migrations. This accounts for the greater diversity of species that are found in marine ecotones. Shore peoples have been historically more heterogeneous than inlanders, more likely to intermarry with strangers, more open to cultures brought from afar. Part of this is due to the wider range of their own travel, and their greater dependency on the kindness of strangers in far flung ports of call. European cod fishers of diverse national backgrounds arriving in Newfoundland to begin the fishing season in the modern period maintained a fairly peaceful coexistence by electing an "admiral" to adjudicate disputes until they all returned to Europe at the end of the season. Seafaring is, by nature, cooperative to some degree. Crews have always been mixed. The shore remained a commons, open by law and custom to fishers, hunters, fowlers, and navigators until our own time, when the extension of territorial limits and the privatization of shores have ended ancient practices in the developed world.

Rachel Carson described the shore as a "marginal world," for her a term of admiration rather than, as it has become today, one of denigration,

Today a little more land may belong to the sea, tomorrow a little less. Always the edge of the sea remains an elusive and indefinite boundary (Carson, 1955, p. 1).

It was this marginality that gave shores their superior generativity,

Only the most hardy and adaptable can survive in a region so mutable ... In the difficult world of the shore, life displays its enormous toughness and vitality ... (ibid.).

This explains in part why islanders have been so resilient, so flexible and adaptable. The sea is both friend and enemy. Islanders have shown little tendency to romanticize it, leaving that to mainland landlubbers. Seafarers are sea fearing, fatalistic but not passive. The shore is for them that margin of error that makes all the difference between success and failure. Creating and maintaining margins is a hedge against becoming too reliant on one ecosystem or another. Until recently most fishers were also farmers, going to sea seasonally to supplement their earnings from small holdings. They did not live directly on the coast, but came down to the sea when their prey migrated close to shore. For most of history, mariners have been part-timers, poor people who had no other choice if they were to support themselves and their families. Only very recently has seafaring become a profession, and a not very desirable one at that (Gillis, 2012, pp. 114-121).

160 
Shore people, and islanders in particular, have always been Jacks (and Jills)-of-all trades, which explains how they have survived in often hostile environments. Despite the stereotypes of backwardness attached to them, they stay in touch with advanced worlds, often ahead of their hinterland counterparts in adopting latest ideas and fashions. Today, islanders have little choice but to take on modern practices to survive in a world that harshly impinges on them. Migration is one of their tried and tested means of survival. When the environments of their native lands betrayed them, Pacific islanders picked up their crops and animals to move on, ultimately settling worlds far larger than ever conquered by land-locked peoples. Now they are on the move again, this time sending back remittances that sustain the islands of their birth. There are often more islanders on mainlands than on their islands of origin.

Shore people, and islanders in particular, learn to be adaptable. Living in a transition zone, which is itself always changing and often challenging, they are fully exposed to "edge effects.' Whatever advantages an ecotone may offer, edges are "fraught with tension" (Raphael, 1986, p. 6). This is true not only of biological edges, but also cultural ones. "Cultural ecotones are the pluralistic contexts out of which conflict and change emerge; they are the places where society smooths wrinkles in her skirts" (Krall, 1994, pp. 4-5).

Ecotones are made, not given. Two or more ecosystems may intersect, but an ecotone does not exist unless someone exploits this condition. The shape and size of a given ecotone is also a product of initiative. Human evolution has been ecotonal, starting where forest met savannah, developing at the edges of streams and lakes, and then, in humankind's most stunning leap forward, at the southern tip of Africa some 165,000 years ago. Carl Sauer was one of the first to perceive the shore as original home of humankind, and recent research in the caves at Pinnacle Point, South Africa, confirms the origins of Homo sapiens in the ecotonal conditions of the tidal zone. For millennia, humans have been creating their own edges,

People do not just seek out and live along 'naturally' occurring ecological edges, but intentionally change the temporal and spatial dynamics of ecological systems in order to increase ecological diversity and resource abundance (Turner et al., 2003, p. 451).

Fire has long been used by hunter/gatherer peoples to clear heavy forests, opening up clearings for plant growth, both for harvesting and to attract large animals for kill or capture. When Europeans arrived in the Americas, they found a mosaic of intersecting ecosystems created by Native American burning practices. They expanded upon these, creating still more ecotones conducive to their own forms of agriculture and animal husbandry (Turner et al., p. 448). The same was true of the shores, where local peoples had already learned to shape the tidal ecotone to enhance the clam and oyster harvest. On the northwest coasts of America, shore societies, as rich culturally as they were materially, had already reshaped the intertidal zone.

As Rowan Jacobsen has reminded us in his fine study of Native American oyster cultures, "we are made for - and made by - that thin world where land meets sea" (Jacobsen, 2009, p. 28). The Haida people occupied a waterland that they called xhaaydla, which was neither land nor sea, but both, living in a different kind of space but also on a different kind of time, much more attuned to daily, monthly, and seasonal rhythms of the sea (Leeming \& Leeming, 1994, pp. 13-14). They not only lived at the edge of the sea, but knew how to live with the sea, in a manner that has been largely lost today, even among islanders. 
Islands are notorious shape changers. Because shores are fractal rather than linear; their exact dimensions are hard to pin down. They change with every tide, with major storms and earthquakes. Our ancestors were right in thinking of them as moving or floating, as alive, for, like shores, they are elusive and indefinable. In places of great seismic activity, they are known to rise suddenly and disappear just as quickly. Both the Atlantic and the Pacific are full of vanished islands, some quite real, others fanciful (Nunn, 2009).

But islanders' relationship to their habitat is also extraordinarily variable, as Canada's Prince Edward Island demonstrates. Until quite recently, its people were deeply engaged with the sea, approaching it as a resource, but seeing it as a place of toil and danger, to be avoided during leisure hours. They built well back from the shore and faced their houses away from the sea. Those who frequented the island's magnificent beaches were described as "chasin' the shore," seen as eccentric, even a little mad. It was tourists who first colonized the shore, building to the edge of the sea. It was only when native islanders began to disengage with the sea they too began to chase the shore, though many are now priced out of the choicest seaside locations (Weale, 2007, p. 10).

Mainlands have colonized islands, but the reverse is also true. Islands have provided platforms from which previously under-populated mainlands were colonized. Island environments were also transplanted to continents. In the case of early agriculture, it moved from the Levant to Aegean isles, and then onto the Greek mainland, where it spread to northern Europe. In the case of northwestern Europe, coasts and islands played a key role in the Stone Age, as hunter gatherers moved along its Atlantic edge. They settled in rich estuaries and moved inland along rivers. But it was on islands that western Europeans first took up permanent residence, combining agriculture with fishing and shellfish gathering. "It was the sea that set the pace" (Cunliffe, 2008, p. 120).

\section{Hardening of edges}

Of course, the water-land relationship differs from island to island. Large islands resemble continents, with their own interior ecosystems, less impacted by oceans; unlike smaller islands whose climates, biota and human occupants are inseparable from the surrounding sea. Small island inhabitants have been an edge species, moving back and forth across the tide line, at the same time exploiting land and sea. They have been part of the loop of shoreline and life (Raban, 1988); their movements more cyclical than linear as they exploit daily, monthly, and seasonal changes to harvest both land and sea-based riches. Hunter-gatherers had long ranged deep inland and far offshore on a seasonal basis. Europeans would extend their hunting and fishing practices temporally and spatially, ultimately making the whole world an ecotone of resources. In the case of whaling, what had been a local edge became a global one.

Around the globe, the loop has now been shattered, and coastal dwellers, insular as well as continental, are no longer true edge species, except for their geography. With rare exceptions, islands have become less ecotonal. Coasts are increasingly armoured and wetlands have disappeared, thereby severing a particularly rich connection between land and sea. And islanders now no longer experience the connections between the two as they once did. Except in the underdeveloped world, it is rare for farmers to fish, or fishers to farm. With the industrialization of the world's fisheries, connections between land and sea have been severed. 
Fishing fleets have become footloose and crews internationalized. Many ships are now registered in foreign lands, some of them landlocked. They no longer have home ports. In the age of container ships, crews often do not even set foot on the lands they visit (George, 2013).

It is not just that the natural environment of islands has changed, but both island and continental populations have altered their attitudes toward both land and sea. Islanders. particularly in the Atlantic and the Mediterranean, have become more continental in their habits and perspectives. For them, the sea has become an alien world. It is only when hurricanes, tsunamis and oil spills strike that they are reminded that they live in an ecotone, a waterland. For thousands of years in Japan, an awareness of living not just on but with the sea has been part of coastal consciousness. To remind themselves of its cruelty, Japanese villagers erected so-called "tsunami stones" to mark the farthest extent of inundation and to encourage people to build on higher ground. But recently the stones have been ignored and building on the shore has increased, encouraged by state-financed construction of massive seawalls that, as the 2011 tsunami disaster showed, produced a false sense of security. The eventual devastation must be considered not so much a natural as a human disaster (Gillis, 2012, pp. 191-2).

On the coasts of North America, as well as in Europe and Japan, affluent populations now crowd the shore. But only a tiny minority of coastal residents has any idea of how to live with the sea. In the past, shores were colonized from the sea. Today, the newcomers are mainly inlanders, who have no notion of how earlier generations coped. Shores are the least understood part of our geography and history. In the absence of any sense of their past, the tendency has been to reach for technological fixes, such as seawalling, which have only increased the rate of coastal erosion. In the long run, the only sensible solution is to accept the sea and its dangers, to build well back from the shore, to beat a strategic retreat. But there is something that property owners and governments (the latter dependent on shore property for taxes and tourism) have been reluctant to do. Yet, there is really no option if we are to adapt successfully to the climate changes that are already upon us (Pilkey \& Young, 2009).

The terms shore and coast are often used interchangeably, when, in fact, they have different and conflicted histories. Before there were coasts, there were shores. The coast line was an eighteenth century invention, a fiction inscribed on a fractal environment that bore no likeness to its smooth, continuous contours. The modern notion of coasts was called into being by the rise of the continental nation state, which needed something that appeared to be a fact of nature to reinforce its fragile boundaries. We are now entering into a post-continental era, when shores are again the focus of attention (Lewis \& Wigen, 1997). For two hundred years, national histories began and ended at coastlines. Now, what were once seen as natural borders are in question. There are 160 uncontested marine borders, but 270 others that are challenged (Diener \& Hagen, 2012, pp. 76-78). And islands are again the focus of international tensions, not so much because of the lands themselves but the fishing in surrounding waters and the mineral riches that expanded territorial zones give them access to. With so much attention focused on what lies offshore and under the sea, the world looks a great deal more terraqueous: a sea of islands, with emphasis on the sea as a material and strategic resource (ibid., chapter 4).

Global history has made us wary of reifying political borders, but we must be prepared to treat so-called natural boundaries as equally liquid. Land and water constitute an ecological continuum. We need to be wary of distinguishing the marine too sharply from the terrestrial. So-called "blue water history" has vastly exaggerated the importance of the deep seas at the 
expense of near shore waters, where most of the world's fishing and shipping has always taken place. Perhaps it is time to focus on what might be called "brown water history" in order to better understand those ecotonal places which have been so central to human evolution.

\section{The necessity of margins}

Until quite recently, shores have been regarded as marginal. Shore peoples and particularly island peoples have been of secondary interest to historians and geographers. But now we are beginning to appreciate the centrality of the marginal. Take the lowly hedgerow, for example. For most of the twentieth century, thousands of kilometres of hedgerow have been destroyed in the name of agricultural modernization. But now this ecotonal feature is again recognized as vital to the health of the fields it borders, and to the maintenance of biodiversity generally, After decades of ploughing right up to the edges of their fields, farmers have begun to become aware of the vulnerability of monocultures, the disappearance not only of plant, but animal and bird species. Lately, farmers are again hedging their fields, creating ecotones between forest and field, streams and pastures to prevent erosion and pollution, thereby hedging their bets against blight (pun intended).

An appreciation of margins is occurring everywhere. We now know the losses that occur when rivers are straightened and channelled, eliminating their meandering margins, cutting them off from their ancient flood plains. And now we are suddenly aware of the effect that the hardening of coasts has had on the ability of shores to maintain their own health and that of shore populations. When beaches are seawalled, dunes levelled, and shores built on, some of the most fertile margins of the world - wetlands, deltas, estuaries - disappear in an astonishingly short time. The result is not a shore that is a more stable and protected coast: but one that is significantly more vulnerable than ever before.

It is in this moment of ecological crisis that we are rediscovering the need for margins. "If change is to come, then, it will have to come from the outside. It will have to come from the margins" (Berry, 1986. pp. 174, 223). We need to support margins. "As a matter of urgency we just cannot go on thinking of them as 'in-between'. We must choose to include them on this side of human social practices, to factor them into our political decision" Mason (2007, p. 51).

We humans are an edge species, but we must not to allow our edges to harden into barriers rather than perform as seams that afford connections vital to our social and environmental health. It might be better to think of ourselves as a margins species, because the margin is "embracing and open, in contrast to an edge, which emphasizes alterity and difference ..." (Casey, 2013, p. 79). Edges divide places, margins bring them together. Margins are a space of flows; edges belong to fixed places of stasis. This is also true of the temporal dimensions of margins: at an edge, time's arrow is unidirectional; in margins, time is cyclical. Edges belong to a world of linearity, margins to the realm of circularity. An edge is by definition something "in-between," without a substance of its own. It always belongs to something else. It has no history or geography of its own. As a momentary transit point on the way to elsewhere, an edge is not a place in its own right or a time apart with its own duration and rhythms. Margins are humanly habitable, edges are not. Margins encourage humans to connect and communicate. They are the seams that facilitate exchange and communication. Unlike edges, which call a halt, margins invite entry and allow escape. 
Shores are classical margins; as Rachel Carson argued, they are elusive and indefinable. By turning them into coasts, fixed and lifeless extensions of land, we thought we were protecting them and ourselves. However, the hard edges we have designed to fend off disaster betray us time and again. Seawalls increase the force of wave action and lead to greater coastal erosion (Gillis, 2012, pp. 191-2). The barriers and hardened harbours the Japanese erected to defend themselves against tsunamis only worsened the damage in 2011. Straightening the Mississippi river did not stem massive flooding, but deprived its contiguous farmlands of vital nutrients. Damming and straightening rivers has been disastrous to fish life, animals and the peoples that rely on them. Failing to provide broad enough temporal and spatial margins of error has proven to be a blunder that we are only now starting to recognize and correct.

\section{Acknowledgements}

I am grateful to Ken Kollman, Director, and the staff at the International Institute, University of Michigan, Ann Arbor MI, USA, for inviting me to deliver an earlier version of this paper at a day-long symposium on the future of islands, November 1, 2013. I also thank Prof. David Hancock for comments on an earlier draft, which helped me bring my paper to its present form.

\section{References}

Beer, G. (1990). The island and the aeroplane: the case of Virginia Woolf. In H. Bhabha (Ed.) Nation and narration (pp. 265-290). London: Routledge.

Berry, A. (2007) Evolution. In G. Baldacchino (Ed.) A world of islands: An island studies reader (pp. 143-174). Charlottetown, Canada and Luqa, Malta: Institute of Island Studies, University of Prince Edward Island and Agenda Academic

Berry, W. (1986). The unsettling of America: Culture in agriculture. San Francisco: Sierra Club. Bolster, W. J. (2012). The mortal sea: Fishing the Atlantic in the age of sail. Cambridge MA: Harvard University Press.

Broodbank, C. (1999). Insularity of island archaeologists: comments on Rainbird's 'Islands out of time.' Journal of Mediterranean Archeology 12(2), pp. 235-239.

Carson, R. (1955). The edge of the sea. Boston MA: Houghton Mifflin.

Casey, E. S. (2013). The fate of place: A philosophical history. Berkeley CA: University of California Press.

Cunliffe, B. (2008) Europe between the oceans: Themes and variations, 9000 BC to AD 1000. New Haven CT: Yale University Press.

DeLoughrey, E. M. (2013). The myth of isolates: ecosystem ecologies in the modern Pacific. Cultural Geographies, 20(2), pp. 167-194.

Diener, A. R., \& Hagen, J. (2012). Borders: A very short introduction. Oxford: Oxford University Press, pp. 76-78.

Eriksen, T. H. (1993). In which sense do cultural islands exist? Social Anthropology, 1(1), pp. 133-147.

George, R. (2013). Ninety percent of everything: Inside shipping, the invisible industry that puts clothes on your back, gas in your car and food on your plate. New York: Metropolitan Books. 
Gillespie, R. G., \& Clague, D.A. (eds) (2009). Encyclopedia of islands. Berkeley CA: University of California Press.

Gillis, J. R. (2004). Islands of the mind: How the human imagination created the Atlantic World. New York: Palgrave Macmillan.

Gillis, J. R. (2013). The human shore: Seacoasts in history. Chicago: Chicago University Press. Gasstner, C. B. (1983) Rachel Carson. New York: Frederick Unger.

Hayward, P. (2012). Aquapelagos and aquapelagic assemblages. Shima: The International Journal of Research into Island Cultures, 6(1), pp. 1-11.

Jacobsen, R. (2009). The living store: Rediscovering a lost world. New York: Bloomsbury.

Krall, F. R. (1994). Ecotone: Wayfaring in the margins. Albany, New York: State University of New York Press.

Leeming, D., \& Leeming, M. (Eds.) (1994). A Dictionary of creation myths. Oxford: Oxford University Press.

Lewis, M. L., \& Wigen, K. E. (1997). The myth of continents: A critique of metageography. Berkeley CA: University of California Press.

Mason, T. (2007). Ecology without nature: Rethinking environmental aesthetics. Cambridge MA: Harvard University Press.

Nunn, P. D. (2007). Origins and environments. In G. Baldacchino (Ed.) A world of islands: An island studies reader (pp.107-142). Charlottetown, Canada and Luqa, Malta: Institute of Island Studies, University of Prince Edward Island and Agenda Academic.

Nunn, P. D. (2009). Vanished islands and hidden continents in the Pacific. Honolulu HI: University of Hawai'i Press.

Pearson, M. N. (2005). Littoral society: the case for the coast. In The world of the Indian Ocean: 1500-1800 (pp. 1-8). Aldershot: Ashgate.

Pearson, M. N. (2006). Littoral society: the concept and the problem. Journal of World History, 17(4), pp. 353-373.

Pilkey, O. H.,\& Young, R. (2009). The rising sea. Washington DC: Island Press.

Pope, P. (2004). Fish into wine: The Newfoundland plantation in the Seventeenth Century. Chapel Hill NC: University of North Carolina Press.

Raban, J. (1988). Coasting: A private voyage. New York: Penguin.

Rainbird, P. (1999). Islands out of time: towards a critique of island archaeology. Journal of Mediterranean Archeology, 12(2), pp. 216-232.

Raphael, R. (1986). Edges: Human ecology of the backcountry. Lincoln NE: University of Nebraska Press.

Steinberg, P. E. (2001). The social construction of the ocean. Cambridge: Cambridge University Press.

Stratford, E., Baldacchino, G., McMahon, E., Farbotko, C., \& Harwood, A. (2011). Envisioning the archipelago. Island Studies Journal, 6(2), pp. 113-130.

Turner, N. J., Davidson-Hunt, I. J., \& O'Flaherty, M. (2003). Living on the edge: ecological and cultural edges as sources of diversity for social-ecological resilience. Human Ecology, 31(3), pp. 439-461.

Weale, D. (2007). Chasin the shore: Little stories about spirit and landscape. Charlottetown, Canada: Tangle Lane. 